
$\$$ Research Square
Preprints are preliminary reports that have not undergone peer review.
They should not be considered conclusive, used to inform clinical practice, or referenced by the media as validated information.

\title{
Sociodemographic Factors Associated With HPV Awareness/Knowledge and Cervical Cancer Screening Behaviors Among Caregivers in the US
}

\author{
Jiyeong Kim ( $\square$ jiykim@ucdavis.edu ) \\ University of California, Davis \\ Melanie Dove \\ University of California, Davis \\ Julie HT Dang \\ University of California, Davis
}

\section{Research Article}

Keywords: Human Papillomavirus (HPV), HPV awareness, Cervical cancer screening, Caregivers, Health disparities, sociodemographic

Posted Date: December 20th, 2021

DOI: https://doi.org/10.21203/rs.3.rs-1120326/v1

License: (9) (1) This work is licensed under a Creative Commons Attribution 4.0 International License. Read Full License 


\section{Abstract}

Background. Family caregivers may be at a higher risk for several chronic diseases including cancer. Cervical cancer is one of the most prevalent cancers among U.S. women. Despite family caregivers' vulnerability, the status of their HPV awareness, knowledge, and preventive health behaviors, including cervical cancer screening, have been understudied. Thus, this study aimed to examine the sociodemographic factors associated with HPV awareness and knowledge, and adherence to the cervical cancer screening guidelines among caregivers in the U.S.

Methods. Nationally representative cross-sectional survey data were obtained from the Health Information National Trends Survey (HINTS $5,2017-2020)$. Only female caregivers, aged $21-65$, were included $(N=834)$. Weighted multivariate logistic regression was performed to identify factors associated with HPV awareness, knowledge, and adherence to the United States Preventive Service Task Force cervical cancer screening guidelines (by age, race/ethnicity, education, household income, marital status, employment status, and health insurance type).

Results. Caregivers who were older (aged 51-65 vs. 21-50), were less educated (high school graduate or less vs. some college or more) showed lower adherence to the cervical cancer screening guidelines (every 3 years) than their counterparts. Caregivers who were older and less educated showed lower HPV awareness (Heard of HPV).

Conclusions. There are caregiving populations whose HPV awareness, knowledge and cervical cancer screening adherence are low. To improve their awareness and knowledge of HPV and support their cervical cancer screening behaviors, we need to consider interventions that target those specific populations.

\section{Introduction}

Approximately 53 million individuals were family caregivers in the U.S. in 2020.(1) More than one in five people (21\%) provided unpaid healthcare or functional needs for their family members. (1) This is a 9.5 million increase from 2018 (43.5 million), and the family caregiving population is projected to continue to increase.(1) Caregivers are often described as hidden patients because caregiving is burdensome as it requires physical, emotional, financial sacrifices and is usually a long-term commitment, spanning from several years to over a decade.(2) About a quarter of caregivers (26\%) report spending over 20 hours per week providing care.(3) Consequentially, this population is vulnerable to an unhealthy lifestyle and are at high risk for chronic diseases.(4-7) Prolonged caregiving causes cumulated stress, including neurohormonal changes and inflammatory responses in the body, weight loss, and sleep deprivation. $(8,9)$ According to the caregiver data from the Behavioral Risk Factor Surveillance System (BRFSS), in 2015-17, 14.5\% of caregivers experienced an unhealthy mental status for 14 and more days in the past month,(10) $17.6 \%$ had an unhealthy physical status for 14 days or more in the past month, and $36.7 \%$ reported insufficient sleep (less than 7 hours of sleep).(10) Moreover, $40.7 \%$ of caregivers reported multiple chronic medical conditions, including coronary heart disease, stroke, asthma, chronic obstructive pulmonary disease (COPD), arthritis, depressive disorder, kidney disease, diabetes, and cancer.(10)

The majority of caregivers are female (61\%),(3) and the average age of female caregivers is 50.1 years.(1) Cervical cancer is one of the most prevalent cancers among women in the U.S. and the average age at diagnosis is 50.(11) It is also one of the most common causes of cancer death among U.S. women.(11) For most types of cervical cancer, Human Papilloma Virus (HPV) infection is the primary cause, specifically HPV I6 and 18.(12) Approximately 80 million people in the U.S. are currently infected with HPV.(13) While the majority of HPV infections disappear naturally within 1 to 2 years; (12) persistent high-risk HPV can cause cancers of the cervix, penis and anus.(12) Papanicolaou cytology (Pap smear) detects changes in cells caused by HPV and allows at-risk women to receive treatment before it becomes invasive carcinoma.(14) As early detection can reduce cervical cancer incidence and mortality significantly, active cervical cancer screening is strongly recommended as an effective prevention strategy. The U.S. Preventive Services Task Force (USPSTF) recommends cervical cytology every 3 years for women aged 21 to 29 years old, and for women aged 30-65 years old, either cervical cytology every 3 years, high-risk Human Papilloma Virus (hrHPV) testing every 5 years, or hrHPV testing in combination with cytology (cotesting) every 5 years.(15) In 2018, 12,733 new cervical cancer cases and 4,138 cervical cancer death were reported despite effective prevention and treatment options. $(16,17)$

Despite the threat of cervical cancer, knowledge regarding the cause of cervical cancer and the linkage to HPV infection has been low to moderate among Americans.(18-20) Furthermore, HPV knowledge level differs by sociodemographic characteristics (e.g., race/ethnicity, age, income, educational attainment, insurance status, rurality of residence).(20-27) HPV knowledge level was lower in racial/ethnic minorities, including Hmong American immigrants, Korean American immigrants, and Hispanics, older populations, and rural residents. $(20-27)$ 
Adherence to the cervical cancer screening guidelines (e.g., pap smear within the past 3 years) has been moderate to high.(28, 29) Previous analysis of HINTS data (2013-14) revealed that $81.3 \%$ of 21-65 years of women reported that they had a Pap smear in the past 3 years.(30) However, stark disparities by sociodemographic factors were observed in cervical cancer screening behavior.(2, 3, 35, 4, 8, 9, 28, 31-34) Similar to the HPV knowledge level, the Pap smear test was less utilized in women who were older and racial/ethnic minorities (African American, Asians, Hispanics).(3, 34, 35) Also, low Socioeconomic Status (SES), including low income, low educational attainment, no health insurance, absence of a usual source of healthcare, was significantly associated with low adherence to obtaining cervical cancer screening. $(2,4,8,9,31-33)$

Reportedly, HPV knowledge level is an essential indicator in cervical cancer screening utilization as these two are positively associated with each other.(36, 37) Multiple studies have reported this association based on their empirical research or nationally representative survey data analysis. $(36,37)$ This relationship is also supported by the Theory of Reasoned Action, a theory explaining how intention and health behaviors are related. $(5,6)$

While multiple studies have shown disparities in HPV knowledge and cervical cancer screening behavior in women in the U.S., studies focused on family caregivers' negative health behaviors due to the caregiving burden and the receipt of preventive clinical services, including cancer screening, are still scant with inconsistent results.(38-47) Some studies presented caregivers' adherence to the Pap smear test being low because of caregiving.(38-41) Other studies reported no association between caregiving status and Pap smear utilization.(39, 42,43) Studies have also suggested that the caregivers are more aware of the preventive health services and hence actively participating in cancer screening.(44-47)

Despite the limited findings, there has been a longstanding concern that caregivers are less likely to perform cancer screenings because the burden of caregiving may hinder them from obtaining care for themselves and their health status is already vulnerable.(4-7, 38-41) In addition, the burden of caregiving and the association of chronic medical conditions also differed by sociodemographic characteristics. Family caregivers who are women, racial/ethnic minorities, rural residents, and with low income experienced heavier caregiving burdens,(7, 48-52) and also presented with worse health conditions. $(50,53-55)$ While we can reasonably assume that subgroups of caregivers are disproportionately low in cervical cancer screening and HPV knowledge, little is known in this area. Given the caregivers' crucial role in patients' disease management, treatment compliance, resilience, and mental and spiritual support, and family functioning, and the persisting nature of caregiving, this population needs additional support on the importance of obtaining and adhering to cervical cancer screening recommendations. Therefore, this study aimed to identify sociodemographic factors associated with disparities in HPV knowledge and cervical cancer screening behaviors among caregivers in the U.S. This information will contribute to the development of a targeted intervention to interpose existing inequities in this area.

\section{Methods}

\section{Data source}

This study used publicly available cross-sectional data, Health Information National Trends Survey (HINTS).(56) HINTS is a selfadministered nationally representative survey data collected by the National Cancer Institute. The present study used HINTS 5 Cycle $1,2,3,4$ in 2017-2020. HINTS 5 is a random digit-dialed telephone survey and a mailed questionnaire survey in non-institutionalized civilians aged 18 and older in the US. HINTS 5 included data of caregiver population, their health-related behavior, perception, and knowledge of the disease. Geographic addresses were stratified by either area with a high concentration of minority population or low concentration of minority population in HINTS 5 Cycle 2,3,4. HINTS 5 Cycle 1 included one more stratification in geographic address, counties of Central Appalachia. The present study followed the Strengthening the Reporting of Observational Studies in Epidemiology (STROBE) guideline.(57)

The total number of respondents used in this study was 16,092 (3,285 in Cycle 1, 3,504 in Cycle 2, 5,438 in Cycle 3, 3,865 in Cycle 4). Each response rate was $32.4 \%, 32.39 \%, 30.3 \%, 36.7 \%$, respectively. The response rate was estimated based on Response Rate 2 formula (RR2) from the American Association of Public Opinion Research.(58) In our analysis, we only included female caregivers aged 21-65 ( $\mathrm{n}=834$ ) because that is the population recommended to obtain a regular cervical cancer screening every 3 years by the USPSTF.

\section{Caregiver status}

Caregiving status was identified by one question; "Are you currently caring for or making health care decisions for someone with a medical, behavioral, disability, or other conditions?" Those who affirmatively responded 'yes' were defined as caregivers.

\section{Outcome variables}




\section{HPV Awareness (Heard of HPV) and HPV Knowledge (HPV can cause cervical cancer)}

To investigate caregivers' awareness of Human Papillomavirus (HPV), the following survey questions were used; "Have you ever heard of HPV? HPV stands for Human Papilloma Virus. It is not HCV, HIV, or Herpes." Those who answered "yes" were considered to have HPV awareness. Respondents who answered "yes" to the question, "Do you think HPV can cause cervical cancer?" were regarded as having knowledge of the causal effect of HPV on cervical cancer in this study.

\section{Cervical cancer screening adherence to the screening guidelines (Had a pap test within 3 years)}

To distinguish the caregivers who are complaint with the USPSTF cervical cancer screening guidelines, the question, "How long ago did you have your most recent Pap test to check for cervical cancer?" was used. Those who answered, "I have never had a Pap test" were recoded to "Never." Caregivers with all other answers were divided into "within guidelines" if they had a pap test within the past 3 years or "outside guidelines" if they had a pap test more than 3 years ago.

\section{Covariates}

Conceptual framework of social determinants of health from the Healthy People 2030 was applied for the choices of sociodemographic predictors in this study(59): Age (21-50, 51-65), birth gender, race/ethnicity (White, Hispanic, African American/Black, Others including Asian, Native Hawaiian/Pacific Islander, American Indian/Alaska Native, Multiple races), household income (less than \$20,000, $\$ 20,000$ to less than $\$ 35,000, \$ 35,000$ to less than $\$ 50,000, \$ 50,000$ or more), educational attainment (high school graduate or less, some college or more), marital status (married or living with a romantic partner as a married vs. not married including divorced, widowed, separated, single/never been married), employment status (employed vs. unemployed including homemaker, student, retired, disabled), health insurance type (insured by employment or private insurance, Tricare/VA/Indian Health Services, Medicare, Medicaid.)

\section{Statistical Analysis}

The weighted percent of each outcome was estimated for each demographic characteristic. To examine the association between characteristics and the three outcomes of interest (1) HPV awareness, 2) HPV knowledge, 3) adherence to the cervical cancer screening guidelines weighted multivariate logistic regression was performed to present odds ratios and $95 \%$ confidence intervals (Table 3 ). The statistical significance was determined at p-value is less than 0.05 and alpha is 0.05 . All estimates accounted for the sampling strategy using replicate weights and survey procedures in SAS (SAS Studio, version 9.4, Cary, NC).

\section{Results}

Among female caregivers aged $21-65,39 \%$ were aged 51-65, 64\% were non-Hispanic White, $46 \%$ reported less than $\$ 50,000$ annual household income, $25 \%$ were high school graduate or less education, $60 \%$ were employed, $64 \%$ were married, $67 \%$ were insured by the employment-based or private plan while 33\% was insured by the government provided insurance (Medicare, Medicaid, Tricare, VA, Indian Health Services), and approximately $98 \%$ was urban (metropolitan, micropolitan, and small town) residents. (Table 1 ).

HPV Awareness (Heard of HPV) and HPV knowledge (HPV can cause cervical cancer)

Approximately 79\% of female caregivers (aged 21-65) heard of HPV and the majority of participants thought that HPV can cause cervical cancer (98\%) (Table 2). However, disparities in HPV awareness were found by sociodemographic characteristics (Table 3). Younger female caregivers $(21-50)$ were over 2 times more likely to have heard of HPV compared to older caregivers $(51-65)(0 R=2.67,95 \% \mathrm{Cl}=1.61$, 4.41). Female caregivers whose educational attainment was high school graduate or less were one third times likely to have heard of HPV than individuals with some college or more (OR=3.10,95\% $\mathrm{Cl}=1.16,5.79$ in some college or more group).

Adherence to the Cervical Cancer Screening Guidelines (Had a pap test within 3 years)

Overall, $83 \%$ of female caregivers had a pap test in the past 3 years (Table 2 ). Sociodemographic disparities were also found (Table 3 ). Younger caregivers $(21-50)$ were more likely to follow the cervical cancer screening guidelines than older caregivers $(51-65)(0 R=3.47$, $95 \% \mathrm{Cl}=2.01,5.98)$. Other ethnic groups, including Asian, Native Hawaiian/Pacific Islander, American Indian/Alaska Native, Multiple races were more likely to adhere to the cervical cancer screening guidelines than Hispanic female caregivers $(0 R=4.63,95 \%=1.05,20.38)$. Caregivers with some college or more education were nearly 2 times likely to adhere to the cervical cancer screening guidelines than those with high school graduate or less education $(\mathrm{OR}=2.08,95 \% \mathrm{Cl}=1.16,3.74)$. 


\section{Discussion}

This study assessed sociodemographic factors associated with HPV awareness (heard of HPV), HPV knowledge (HPV can cause cervical cancer), and adherence to the cervical cancer screening guidelines (had a pap test within 3 years) among female caregivers in the U.S. from 2017-2020. In general, the older age group, Hispanics, those with low education, were less likely to have awareness and knowledge of HPV and adhere to guidelines.

Our results were similar to Blake et al.(60) who reported lower levels of HPV awareness among women who were older, less educated, had lower-income, had no health insurance, and were of a racial/ethnic minority (Hispanics). One plausible explanation could be that HPV awareness and HPV vaccination campaigns target younger age groups. Healthcare professionals also focus more on younger age groups to promote HPV vaccine uptake and HPV awareness. Thus, older generations, aged 51-65, are less likely to be exposed to these HPV campaigns and educational efforts.

Previous literature reported differences in HPV knowledge level by race/ethnicity, specifically lower knowledge among U.S. racial/ethnic minorities including Hmong American immigrants, Korean American immigrants, and Hispanic women. $(23,24,26,27,61)$ Although other ethnic groups, including Asian female caregivers, were less likely to know about HPV than non-Hispanic Whites, African American/Blacks, and Hispanics in this study, it was not significant. Prior studies that examined HPV knowledge among the general population revealed that age, $(21,23)$ as well as socioeconomic status (income and educational attainment, rurality of residence) $(20-22,24)$ was also associated. However, socioeconomic factors, including household income, educational status, were not associated with HPV knowledge in this population. Presumably, individuals with higher education and higher income are more likely to have higher health literacy and greater access to health resources which can possibly increase their knowledge and awareness of HPV. However, this hypothetical relationship was not observed in this study. One explanation could be that only participants who answered that they have had heard of HPV, were asked subsequently, "Do you think HPV can cause cervical cancer?". In other words, people who are already aware of HPV are more likely to know the causation of cervical cancer which may make it more challenging to associate additional socioeconomic disparities in HPV knowledge among this population. Additionally, this made the sample size of those with HPV knowledge even smaller, which may have resulted in non-significant differences in some of the socioeconomic factors. This can be the limitation of HINTS 5 data to precisely analyze variables related to HPV knowledge. Further comprehensive analysis to examine the association of socioeconomic characteristics and HPV knowledge among female caregivers with a larger sample will be necessary.

Prior studies reported that older age,(62-64) low income, $(2,8)$ low educational attainment, $(2,4,8,33)$ lack of health insurance,(2, 8, 33) marital status, $(2,4,33)$ was associated with low cervical cancer screening rates (within 3 years) among US women. Johnson et al(63) reported younger age groups had higher odds of having a pap test within 5 years than older age groups in general US women. Similar associations were observed in the present study. Although most ( $93 \%$ or higher) female caregivers reported ever having a Pap smear in the past, many subgroups did not adhere to the cervical cancer screening guidelines of every 3 years. Healthy People 2030 aimed to reach $84.3 \%$ of adherence to the cervical cancer screening guidelines among U.S. women.(65) In our analysis, the younger age group (aged 2150) showed satisfied status to reaching the goal (91\%) while the older age group (aged 51-65) was far behind the target (75\%). Considering the average diagnosed age of cervical cancer in the U.S. is 50 , the older age group is the one who needs our attention to improve and maintain their adherence to the USPSTF guidelines. Education was significantly associated with the adherence to the cervical cancer screening guidelines in both general women and caregivers. Women with low educational attainment (high school graduate or less education) showed lower odds of cervical cancer screening behaviors than those with higher educational attainment (4-year college and more education) in general women (63), and this trend was the same in the caregiver population in this study. However, low household income was not significantly associated with the adherence of cervical cancer screening guidelines among caregivers in this study, although low-income earners (annual household income $<\$ 30,000$ ) showed lower odds in obtaining cervical cancer screening within 5 years among U.S. women in previous studies $(63,66)$. The association of age and the adherence to the cervical cancer screening guidelines could be explained by the relationship that low HPV awareness and knowledge is closely related to the low HPV screening behavior.(36, 37) Thus, older caregivers who have low HPV awareness are less likely to obtain cervical cancer screening guidelines. Moreover, it is possible that the caregivers who have low financial resources and educational attainment may be less likely to have heard of HPV and may also be less knowledgeable of HPV. As a result, they may be less likely to acknowledge the importance of HPV screening and have fewer resources, including financial, physical, emotional, to adhere to the recommended cervical cancer screening guidelines. Small sample size could be one potential reason for the no significant association between household income and the adherence to the cervical cancer screening among caregivers. Hence, further comprehensive examination will be necessary with the larger sample population to see whether household income is associated with the adherence to the cervical cancer screening behaviors among caregivers. 
In previous research, women with public health insurance had higher odds in obtaining a cervical cancer screening within 5 years than those with private insurance.(63)

As the coverage of the public insurance has increased since 2016, a study reported that government provided insurance holder's preventive health services utilization rate were also higher than that of non-government insurance holders. However, in this study, significant differences between the health insurance types were not observed in HPV awareness and knowledge, and adherence to the cervical cancer screening guidelines among caregivers. Further research will be necessary to examine the role of health insurance types in adherence to cervical cancer screening behaviors among caregivers. It will help to identify vulnerable subpopulations to improve adherence among caregivers.

Prior studies reported that African-Americans and Hispanics women had lower adherence to cervical cancer screening guidelines than non-Hispanic Whites. $(63,64)$ However, in this study, rather the White caregivers had lower odds in pap test guideline adherence than the Black caregiver's odds when compared to Hispanics, but it was not significant. Other ethnic groups' odds of adherence to the cervical cancer screening guidelines were higher than Hispanics' odds. Further research is recommended to investigate the association of ethnic minorities and adherence to the cervical cancer screening guidelines among caregivers.

\section{Limitation}

The current study has several limitations. First, HINTS is a cross-sectional survey at one point of the year. Hence, it cannot guarantee temporality and causal inference in the outcomes of interests in this study. Second, a low response rate (overall $32 \%$ ) is concerning because those responding to the survey may be different than those who don't and so the survey may not be representative of the target population. Third, the small sample size may be related to some of the non-significant results. Although full sample weights were applied to account for non-response rate and other biases, concerns in representativeness in race/ethnicity may still exist. Lastly, the definition of caregiver may not be precise enough to distinguish the 'ongoing basis multiple-duty medical need-based caretakers' from 'mild (light hours) life aid-based caretakers.' Therefore, the intensity of their caregiving duty was not accounted for in this study. Moreover, this study did not include the rurality of residence as a sociodemographic factor despite the potential association with the disparities in HPV awareness and knowledge as well as adherence to the guidelines of cervical cancer screening. Because nearly $98 \%$ of caregivers were urban residents, we did not think we could have meaningful results out of this population distribution. However, further investigation is needed to better understand how rurality of residence affects caregivers' cervical cancer screening behaviors, including the caregiving burden among rural residents. Although the incidence of invasive cervical cancer was higher in the rural area at every stage (60, 67,68$)$ individuals living in resource-limited or rural areas showed lower rates of cervical cancer screening compared to the general population in the U.S.(69) Female caregivers who are residing in rural areas are experiencing a heavier caregiving burden and presenting with worse health conditions.(50) Previous studies reported the potential barriers to receive cancer screening among rural residents could be a lack of access to care, health insurance coverage, mistrust of healthcare. Along with these potential reasons, periodic cervical cancer screening may be less recommended by the healthcare professionals in rural caregivers. $(70,71)$ This could be partially due to the lack of healthcare services resources, including the shortage of healthcare professionals in rural areas. If a limited number of healthcare professionals are required to cover a large group of rural residents, non-urgent health issues, including preventive services, could be often less prioritized. However, the relationship between rurality and low adherence to the cervical cancer screening guidelines is still unclear.(71, 72 )

\section{Conclusion}

It is important to acknowledge the association between HPV and cervical cancer screening behaviors as higher HPV awareness and knowledge are closely related to higher adherence to cervical cancer screening behaviors.(73, 74$)$ Furthermore, adhering to the recommended cervical cancer screening is crucial for detecting cervical cancer early and reducing mortality significantly.(75, 76) Therefore, targeted intervention to improve HPV awareness and cervical cancer screening adherence will be effective and urgently required among female caregivers as this populations' health condition is at risk.

We found that sociodemographic factors, particularly age, race/ethnicity, educational attainments, were associated with disparities in HPV awareness and adherence to the cervical cancer screening guidelines among female caregivers in the U.S. The value of this study is the suggestion that targeted interventions should focus on women caregivers who are aged 51-65, have low educational attainment (high school graduate or less). Efforts to improve HPV awareness and knowledge as well as adherence to the cervical cancer screening guidelines in this vulnerable subpopulation is needed.

\section{Abbreviations}


- HINTS: Health Information National Trends Survey

- HPV: Human Papillomavirus

- BRFSS: Behavioral Risk Factor Surveillance System

- Pap Smear: Papanicolaou cytology

- USPSTF: U.S. Preventive Services Task Force

\section{Declarations}

\section{- Ethics approval and consent to participate}

Ethics approval and participant consent was not necessary as this study involved the use of a previously-published de-identified database. The data used in the study were publicly available.

All the methods performed in the study followed the relevant guidelines and regulations.

\section{- Consent for publication}

Not applicable.

\section{- Availability of data and materials}

The datasets generated and/or analyzed during the current study are available in the Health Information National Trends Survey, https://hints.cancer.gov/data/default.aspx

\section{- Competing interests}

We declare no competing interests regarding the research, authorship, and/or publication of this article.

\section{- Funding}

There was no funding source for this study.

\section{- Authors' contributions}

JK conceived the study. JK designed the study protocol and conducted literature search under the supervision of JHTD. JK and MD analyzed and interpreted the data. JK wrote the manuscript and JHTD and MD substantially contributed to the manuscript revision.

\section{- Acknowledgement}

Not applicable.

\section{References}

1. Caregiving in the US 2020 | The National Alliance for Caregiving [Internet]. [cited 2021 Aug 21]. Available from: https://www.caregiving.org/caregiving-in-the-us-2020/

2. M H, SS D, N B. Cervical cancer screening among U.S. women: analyses of the 2000 National Health Interview Survey. Prev Med (Baltim) [Internet]. 2004 [cited 2021 Aug 19];39(2):270-8. Available from: https://pubmed.ncbi.nlm.nih.gov/15226035/

3. VM T, TT N, JC J, SJ M. Cervical cancer control research in Vietnamese American communities. Cancer Epidemiol Biomarkers Prev [Internet]. 2008 Nov [cited 2021 Aug 21];17(11):2924-30. Available from: https://pubmed.ncbi.nlm.nih.gov/18990732/

4. LM M, EE C, PA W, CW H. Comparison of mammography and Pap test use from the 1987 and 1992 National Health Interview Surveys: are we closing the gaps? Am J Prev Med [Internet]. 1996 [cited 2021 Aug 21];12(2):82-90. Available from: https://pubmed.ncbi.nlm.nih.gov/8777072/

5. Fishbein M, Ajzen I. Belief, Attitude, Intention, and Behavior: An Introduction to Theory and Research. Philos Rhetor [Internet]. 1977 [cited 2021 Aug 21];10(2). Available from: https://philpapers.org/rec/FISBAI

6. Ajzen I. " Understanding attitudes and predicting social behavior, Englewood Cliffs. Pbk. ed. Journal of Personality and Social Psychology, , Jan 1992, 98-109. Englewood Cliffs N.J.: Prentice-Hall; 1980. 278 p. 
7. Cohen SA, Kunicki ZJ, Nash CC, Drohan MM, Greaney ML. Rural-Urban Differences in Caregiver Burden Due to the COVID-19 Pandemic among a National Sample of Informal Caregivers. Gerontol Geriatr Med [Internet]. 2021 [cited 2021 Aug 6];7. Available from: /pmc/articles/PMC8216387/

8. J H, E K, C K, J Z, S S, M P, et al. The importance of health insurance as a determinant of cancer screening: evidence from the Women's Health Initiative. Prev Med (Baltim) [Internet]. 2000 [cited 2021 Aug 21];31(3):261-70. Available from: https://pubmed.ncbi.nlm.nih.gov/10964640/

9. Selvin E, Brett KM. Breast and Cervical Cancer Screening: Sociodemographic Predictors Among White, Black, and Hispanic Women. Am J Public Health [Internet]. 2003 Apr 1 [cited 2021 Aug 21];93(4):618. Available from: /pmc/articles/PMC1447800/

10. CDC - BRFSS [Internet]. [cited 2021 Aug 21]. Available from: https://www.cdc.gov/brfss/index.html

11. Fontham ETH, Wolf AMD, Church TR, Etzioni R, Flowers CR, Herzig A, et al. Cervical cancer screening for individuals at average risk: 2020 guideline update from the American Cancer Society. CA Cancer J Clin. 2020 Sep;70(5):321-46.

12. HPV and Cancer - National Cancer Institute [Internet]. [cited 2021 Aug 21]. Available from: https://www.cancer.gov/aboutcancer/causes-prevention/risk/infectious-agents/hpv-and-cancer

13. Satterwhite CL, Torrone E, Meites E, Dunne EF, Mahajan R, Cheryl Bañez Ocfemia M, et al. Sexually transmitted infections among US women and men: Prevalence and incidence estimates, 2008. Sex Transm Dis [Internet]. 2013 Mar [cited 2021 Aug 21];40(3):187-93. Available from: https://journals.Iww.com/stdjournal/Fulltext/2013/03000/Sexually_Transmitted_Infections_Among_US_Women_and.1.aspx

14. Cancer Statistics Review, 1975-2016 - SEER Statistics [Internet]. [cited 2021 Aug 21]. Available from: https://seer.cancer.gov/archive/csr/1975_2016/

15. Curry SJ, Krist AH, Owens DK, Barry MJ, Caughey AB, Davidson KW, et al. Screening for cervical cancer us preventive services task force recommendation statement. JAMA - J Am Med Assoc. 2018 Aug 21;320(7):674-86.

16. USCS Data Visualizations - CDC [Internet]. [cited 2021 Aug 21]. Available from: https://gis.cdc.gov/Cancer/USCS/\#/AtAGlance/ 17. Underlying Cause of Death 1999-2019 [Internet]. [cited 2021 Aug 5]. Available from: https://wonder.cdc.gov/wonder/help/ucd.html

18. MK B, RM M, VG P. Knowledge, perceptions, and motivations related to HPV vaccination among college women. J Cancer Educ [Internet]. 2011 Sep [cited 2021 Aug 21];26(3):459-64. Available from: https://pubmed.ncbi.nlm.nih.gov/21336980/

19. Boakye EA, Tobo BB, Rojek RP, Mohammed KA, Geneus CJ, Osazuwa-Peters N. Approaching a decade since HPV vaccine licensure: Racial and gender disparities in knowledge and awareness of HPV and HPV vaccine. Hum Vaccin Immunother [Internet]. 2017 Nov 2 [cited 2021 Aug 21];13(11):2713. Available from: /pmc/articles/PMC5703403/

20. B H, JM B, K C, MT R. Adults' knowledge and behaviors related to human papillomavirus infection. J Am Board Fam Pract [Internet]. 2004 [cited 2021 Aug 21];17(1):26-31. Available from: https://pubmed.ncbi.nlm.nih.gov/15014049/

21. KR M, S S. Predictors of Adults' Knowledge and Awareness of HPV, HPV-Associated Cancers, and the HPV Vaccine: Implications for Health Education. Health Educ Behav [Internet]. 2018 Feb 1 [cited 2021 Aug 21];45(1):68-76. Available from: https://pubmed.ncbi.nlm.nih.gov/28595454/

22. KL W, LR R, DW W, LH M. HPV awareness, knowledge and attitudes among older African-American women. Am J Health Behav [Internet]. 2015 Mar 1 [cited 2021 Aug 21];39(2):204-10. Available from: https://pubmed.ncbi.nlm.nih.gov/25564833/

23. Davlin SL, Berenson AB, Rahman M. Correlates of HPV Knowledge among Low-income Minority Mothers with a Child 9-17 Years of Age. J Pediatr Adolesc Gynecol [Internet]. 2015 Feb 1 [cited 2021 Aug 21];28(1):19-23. Available from: http://www.jpagonline.org/article/S1083318814001466/fulltext

24. AE S, G M, MS G, KA C, MA S, JC S, et al. Barriers to prevention: knowledge of HPV, cervical cancer, and HPV vaccinations among African American women. Am J Obstet Gynecol [Internet]. 2015 Jan 1 [cited 2021 Aug 21];212(1):65.e1-65.e5. Available from: https://pubmed.ncbi.nlm.nih.gov/24983684/

25. KA M, DS S, CJ G, ER H, CA D, DP S, et al. Rural-urban differences in human papillomavirus knowledge and awareness among US adults. Prev Med (Baltim) [Internet]. 2018 Apr 1 [cited 2021 Aug 21];109:39-43. Available from: https://pubmed.ncbi.nlm.nih.gov/29378268/

26. R B, T S, HY L, M K. HPV Literacy and Associated Factors Among Hmong American Immigrants: Implications for Reducing Cervical Cancer Disparity. J Community Health [Internet]. 2016 Jun 1 [cited 2021 Aug 21];41(3):603-11. Available from: https://pubmed.ncbi.nlm.nih.gov/26696118/

27. Lee HY, Choi YJ, Yoon YJ, Oh J. HPV Literacy: The Role of English Proficiency in Korean American Immigrant Women. Clin J Oncol Nurs [Internet]. 2018 Jun 1 [cited 2021 Aug 21];22(3):E64-70. Available from: https://cjon.ons.org/cjon/22/3/hpv-literacy-role-english- 
proficiency-korean-american-immigrant-women

28. T S, S B, A K, I S, G C. The impact of interventions to improve attendance in female cancer screening among lower socioeconomic groups: a review. Prev Med (Baltim) [Internet]. 2010 Apr [cited 2021 Aug 21];50(4):159-64. Available from:

https://pubmed.ncbi.nlm.nih.gov/20093138/

29. Nelson W, Moser RP, Gaffey A, Waldron W. Adherence to Cervical Cancer Screening Guidelines for U.S. Women Aged 25-64: Data from the 2005 Health Information National Trends Survey (HINTS). J Women's Heal [Internet]. 2009 Nov 1 [cited 2021 Aug 21];18(11):1759. Available from: /pmc/articles/PMC2864462/

30. JS L, YN T, C C. Correlates of Cervical Cancer Screening Adherence Among Women in the U.S.: Findings from HINTS 2013-2014. J Prim Prev [Internet]. 2018 Aug 1 [cited 2021 Sep 15];39(4):329-44. Available from: https://pubmed.ncbi.nlm.nih.gov/29876723/

31. M A, JN B, J H, C O, A L, D M. Cervical Cancer Screening Barriers and Risk Factor Knowledge Among Uninsured Women. J Community Health [Internet]. 2017 Aug 1 [cited 2021 Aug 21];42(4):770-8. Available from: https://pubmed.ncbi.nlm.nih.gov/28155005/

32. Limmer K, LoBiondo-Wood G, Dains J. Predictors of Cervical Cancer Screening Adherence in the United States: A Systematic Review. J Adv Pract Oncol [Internet]. 2014 Jan [cited 2021 Aug 21];5(1):31. Available from: /pmc/articles/PMC4093462/

33. CP S, SJ M, T N, S S, SJ S, B N, et al. The effect of access and satisfaction on regular mammogram and Papanicolaou test screening in a multiethnic population. Med Care [Internet]. 2004 [cited 2021 Aug 21];42(9):914-26. Available from: https://pubmed.ncbi.nlm.nih.gov/15319618/

34. American Cancer Society. Cancer Prevention \& Early Detection Facts \& Figures 2019-2020. [Internet]. 2019 [cited 2021 Aug 22]. Available from: https://www.cancer.org/content/dam/cancer-org/research/cancer-facts-and-statistics/cancer-prevention-and-earlydetection-facts-and-figures/cancer-prevention-and-early-detection-facts-and-figures-2019-2020.pdf

35. Fernández LE, Morales A. Language and Use of Cancer Screening Services among Border and Non-Border Hispanic Texas Women. http://dx.doi.org/101080/13557850701235150 [Internet]. 2007 Jun [cited 2021 Aug 21];12(3):245-63. Available from: https://www.tandfonline.com/doi/abs/10.1080/13557850701235150

36. A C, V B, J K, CC T. Understanding Barriers to Cervical Cancer Screening in Women With Access to Care, Behavioral Risk Factor Surveillance System, 2014. Prev Chronic Dis [Internet]. 2016 [cited 2021 Aug 21];13(11):1-8. Available from: https://pubmed.ncbi.nlm.nih.gov/27831682/

37. J H, B H, G C, D E, S C, O E-S, et al. Role of Race/Ethnicity, Language, and Insurance in Use of Cervical Cancer Prevention Services Among Low-Income Hispanic Women, 2009-2013. Prev Chronic Dis [Internet]. 2018 Feb 1 [cited 2021 Aug 21];15(2). Available from: https://pubmed.ncbi.nlm.nih.gov/29470167/

38. PJ B. Family caregiver assessment. Essential for effective home health care. J Gerontol Nurs [Internet]. 2003 [cited 2021 Aug 21];29(2):29-36. Available from: https://pubmed.ncbi.nlm.nih.gov/12640862/

39. C K, MU K, RB W, KM L. Quality of preventive clinical services among caregivers in the health and retirement study. J Gen Intern Med [Internet]. 2004 Aug [cited 2021 Aug 21];19(8):875-8. Available from: https://pubmed.ncbi.nlm.nih.gov/15242474/

40. L M, EL B, EM A, LA A. Examining modifiable health behaviors, body weight, and use of preventive health services among caregivers and non-caregivers aged 65 years and older in Hawaii, Kansas, and Washington using 2007 BRFSS. J Nutr Health Aging [Internet]. 2010 [cited 2021 Aug 21];14(5):373-9. Available from: https://pubmed.ncbi.nlm.nih.gov/20424805/

41. KY S, SM P, CH L, GJ C, D L, S J, et al. Behavioral risk factors and use of preventive screening services among spousal caregivers of cancer patients. Support Care Cancer [Internet]. 2011 Jul [cited 2021 Aug 21];19(7):919-27. Available from: https://pubmed.ncbi.nlm.nih.gov/20445996/

42. L S, BL C. Colon cancer screening among older women caregivers. Cancer Nurs [Internet]. 2000 [cited 2021 Aug 21];23(2):109-16. Available from: https://pubmed.ncbi.nlm.nih.gov/10763281/

43. Reeves KW, Bacon K, Fredman L. Caregiving associated with selected cancer risk behaviors and screening utilization among women: cross-sectional results of the 2009 BRFSS. BMC Public Heal 2012121 [Internet]. 2012 Aug 21 [cited 2021 Aug 21];12(1):1-8. Available from: https://bmcpublichealth.biomedcentral.com/articles/10.1186/1471-2458-12-685

44. K M, S F, J W, M D, A S, J W. Attitudes towards HPV testing: a qualitative study of beliefs among Indian, Pakistani, African-Caribbean and white British women in the UK. Br J Cancer [Internet]. 2003 Jan 13 [cited 2021 Aug 21];88(1):42-6. Available from: https://pubmed.ncbi.nlm.nih.gov/12556957/

45. MS C, TS M, WH K, W Y, B Z. Knowledge, perceptions, and attitudes of Hong Kong Chinese women on screening mammography and early breast cancer management. Breast J [Internet]. 2005 Jan [cited 2021 Aug 21];11(1):52-6. Available from:

https://pubmed.ncbi.nlm.nih.gov/15647079/

Page 9/14 
46. HS J, M K, S S, W H. Predictors of adherence to screening mammography among Korean American women. Prev Med (Baltim) [Internet]. 2004 [cited 2021 Aug 21];39(3):474-81. Available from: https://pubmed.ncbi.nlm.nih.gov/15313086/

47. T Y, A A, N T, E I. Women's breast cancer risk perception and attitudes toward screening tests. J Psychosoc Oncol [Internet]. 2010 Mar [cited 2021 Aug 21];28(2):189-201. Available from: https://pubmed.ncbi.nlm.nih.gov/20391075/

48. Lahaie C, Earle A, Aging JH-R on, 2013 undefined. An uneven burden: Social disparities in adult caregiving responsibilities, working conditions, and caregiver outcomes. journals.sagepub.com [Internet]. 2013 May [cited 2021 Aug 6];35(3):243-74. Available from: https://journals.sagepub.com/doi/abs/10.1177/0164027512446028?casa_token=jcvu70NacfkAAAAA:-

ZWuPW96SfHjZsA8Mwo038Jji07v7-rRjHR_C-qhxGr-z10RqVmy6x2CnsNOe2uU2EjZODjbZWYUzQ

49. Fuller-Thomson E, Nuru-Jeter A, Minkler M, Guralnik JM. Black-White Disparities in Disability Among Older Americans: Further Untangling the Role of Race and Socioeconomic Status. J Aging Health [Internet]. 2009 Aug [cited 2021 Aug 6];21(5):677. Available from: /pmc/articles/PMC2907066/

50. E C, J P, K B. Rural-urban differences in unpaid caregivers of adults. Rural Remote Health [Internet]. 2017 [cited 2021 Aug 6];17(4). Available from: https://pubmed.ncbi.nlm.nih.gov/29166125/

51. L G, N S, P L, M B. Gender differences in burden and depression among informal caregivers of demented elders in the community. Int J Geriatr Psychiatry [Internet]. 2002 [cited 2021 Aug 6];17(2):154-63. Available from: https://pubmed.ncbi.nlm.nih.gov/11813279/

52. Kondeti A, Yadala A, Rajya Lakshmi N, Prakash C, Palat G, Varthya S. Assessment of Caregiving Burden of Family Caregivers of Advanced Cancer Patients and Their Satisfaction with the Dedicated Inpatient Palliative Care Provided to Their Patients: A CrossSectional Study from a Tertiary Care Centre in South Asia. Asian Pacific J Cancer Prev. 2021 Jul 1;22(7):2109-15.

53. Cherry M, Salmon P, ... JD-R in C, 2013 undefined. Factors influencing the resilience of carers of individuals with dementia. cambridge.org [Internet]. 2013 [cited 2021 Aug 6];251-66. Available from: https://www.cambridge.org/core/journals/reviews-inclinical-gerontology/article/factors-influencing-the-resilience-of-carers-of-individuals-withdementia/25E12EB4FF0B0D3DECD0A4043D139E57

54. Environment CS-J of HB in the S, 2013 undefined. Alzheimer's disease caregiver burden: Does resilience matter? Taylor Fr [Internet]. 2013 Nov [cited 2021 Aug 6];23(8):879-92. Available from: https://www.tandfonline.com/doi/abs/10.1080/10911359.2013.803451? casa_token=90KIGN4eFc8AAAAA:0PS8nUE3r9UZ8ZTbXjzX63p_tdID0KDNQ0Ib4kvZrwBMEODWkA46C9A7IYDT0AFFKidcgfA_NLBIFA

55. M B, A K, A S. Health impact on caregivers of providing informal care to a cognitively impaired older adult: rural versus urban settings. Can J Rural Med [Internet]. 2004 [cited 2021 Aug 21];9(1):15-23. Available from: https://pubmed.ncbi.nlm.nih.gov/15603671/

56. Survey Instruments | HINTS [Internet]. [cited 2021 Aug 23]. Available from: https://hints.cancer.gov/data/survey-instruments.aspx

57. E von E, DG A, M E, SJ P, PC G, JP V. The Strengthening the Reporting of Observational Studies in Epidemiology (STROBE) statement: guidelines for reporting observational studies. Ann Intern Med [Internet]. 2007 Oct 16 [cited 2021 Aug 23];147(8):573-7. Available from: https://pubmed.ncbi.nlm.nih.gov/17938396/

58. Standard Definitions Final Dispositions of Case Codes and Outcome Rates for Surveys Revised 2016 RDD Telephone Surveys InPerson Household Surveys Mail Surveys of Specifically Named Persons Mail Surveys of Unnamed Persons Internet Surveys of Specifically Named Persons 2016 T H E A M E R I C A N A S S O C I A T I O N F O R P U B L I C O P I N I O N R E S E A R C H.

59. Social Determinants of Health - Healthy People 2030 | health.gov [Internet]. [cited 2021 Aug 23]. Available from: https://health.gov/healthypeople/objectives-and-data/social-determinants-health

60. Blake KD, Ottenbacher AJ, Finney Rutten LJ, Grady MA, Kobrin SC, Jacobson RM, et al. Predictors of Human Papillomavirus Awareness and Knowledge in 2013: Gaps and Opportunities for Targeted Communication Strategies. Am J Prev Med. 2015 Apr 1;48(4):402-10.

61. Lee HY, Luo Y, Daniel C, Wang K, Ikenberg C. Is HPV vaccine awareness associated with HPV knowledge level? Findings from HINTS data across racial/ethnic groups in the US. https://doi.org/101080/1355785820201850648 [Internet]. 2020 [cited 2021 Aug 21]; Available from: https://www.tandfonline.com/doi/abs/10.1080/13557858.2020.1850648

62. M W, V B, J K, A C, M S. National assessment of HPV and Pap tests: Changes in cervical cancer screening, National Health Interview Survey. Prev Med (Baltim) [Internet]. 2017 Jul 1 [cited 2021 Aug 21];100:243-7. Available from: https://pubmed.ncbi.nlm.nih.gov/28502575/

63. NL J, KJ H, SF S, GD Z. Persistent Disparities in Cervical Cancer Screening Uptake: Knowledge and Sociodemographic Determinants of Papanicolaou and Human Papillomavirus Testing Among Women in the United States. Public Health Rep [Internet]. 2020 Jul 1 [cited 2021 Aug 21];135(4):483-91. Available from: https://pubmed.ncbi.nlm.nih.gov/32516053/ 
64. M B, SH B, M F, RS B. Correlates of cervical cancer screening among underserved Hispanic and African-American women. Prev Med (Baltim) [Internet]. 2004 [cited 2021 Aug 22];39(3):465-73. Available from: https://pubmed.ncbi.nlm.nih.gov/15313085/

65. Increase the proportion of females who get screened for cervical cancer - C-09 - Healthy People 2030 | health.gov [Internet]. [cited 2021 Sep 15]. Available from: https://health.gov/healthypeople/objectives-and-data/browse-objectives/cancer/increase-proportionfemales-who-get-screened-cervical-cancer-c-09

66. S R. The ACA: implications for the accessibility and quality of breast and cervical cancer prevention and treatment services. Public Health Rep [Internet]. 2012 [cited 2021 Aug 21];127(3):340-4. Available from: https://pubmed.ncbi.nlm.nih.gov/22547867/

67. SJ H, RN A, CC T, GM M, B P, LC R. Invasive Cancer Incidence, 2004-2013, and Deaths, 2006-2015, in Nonmetropolitan and Metropolitan Counties - United States. MMWR Surveill Summ [Internet]. 2017 [cited 2021 Aug 21];66(14):1-13. Available from: https://pubmed.ncbi.nlm.nih.gov/28683054/

68. WE Z, AS J, WD J, SR I, AJ F, DE S, et al. Rural-Urban Differences in Cancer Incidence and Trends in the United States. Cancer Epidemiol Biomarkers Prev [Internet]. 2018 Nov 1 [cited 2021 Aug 21];27(11):1265-74. Available from: https://pubmed.ncbi.nlm.nih.gov/28751476/

69. Coughlin SS, Thompson TD, Hall HI, Logan P, Uhler RJ. Breast and cervical carcinoma screening practices among women in rural and nonrural areas of the United States, 1998-1999. Cancer [Internet]. 2002 Jun 1 [cited 2021 Aug 21];94(11):2801-12. Available from: https://acsjournals.onlinelibrary.wiley.com/doi/full/10.1002/cncr.10577

70. LRB L, DP D. Rural-urban differences in HPV testing for cervical cancer screening. J Rural Health [Internet]. 2021 Sep 10 [cited 2021 Oct 4];jrh.12615. Available from: https://pubmed.ncbi.nlm.nih.gov/34506669/

71. H W, S R, J K, PA F, M S, D S. Barriers of colorectal cancer screening in rural USA: a systematic review. Rural Remote Health [Internet]. 2019 [cited 2021 Aug 21];19(3). Available from: https://pubmed.ncbi.nlm.nih.gov/31394041/

72. RB W, A O, N B, S G, E P, KL T, et al. Approaching health disparities from a population perspective: the National Institutes of Health Centers for Population Health and Health Disparities. Am J Public Health [Internet]. 2008 Sep 1 [cited 2021 Aug 21];98(9):1608-15. Available from: https://pubmed.ncbi.nlm.nih.gov/18633099/

73. EL T, CW W, CA V, SB G, EM D. How Is Health Literacy Related to Pap Testing Among US Women? J Cancer Educ [Internet]. 2019 Aug 15 [cited 2021 Aug 22];34(4):789-95. Available from: https://pubmed.ncbi.nlm.nih.gov/29931455/

74. K A, K G. Factors influencing cancer screening practices of underserved women. J Am Acad Nurse Pract [Internet]. 2007 [cited 2021 Aug 22];19(11):591-601. Available from: https://pubmed.ncbi.nlm.nih.gov/17970859/

75. GP G. [Importance of the Pap smear in the age of HPV testing]. Ther Umsch [Internet]. 2021 Mar 1 [cited 2021 Aug 22$] ; 78(2): 93-8$. Available from: https://pubmed.ncbi.nlm.nih.gov/33615865/

76. JR F, EV M, BW J. Cervical Cancer. 2021 [cited 2021 Aug 22];350-1. Available from: https://pubmed.ncbi.nlm.nih.gov/28613745/

\section{Tables}


Table 1

Demographic characteristics of female caregiving population 2017-2020

\begin{tabular}{|c|c|c|c|}
\hline & & Frequency, $\mathrm{n}$ & Percentage, \% (95\% Cl) \\
\hline \multirow[t]{3}{*}{ age (years) } & $21-50$ & 432 & $61.18(56.10,66.25)$ \\
\hline & $51-65$ & 402 & $38.82(33.75,43.90)$ \\
\hline & & 834 & 100.00 \\
\hline \multirow[t]{5}{*}{ Race/ethnicity } & Non-Hispanic White & 461 & $63.55(58.83,68.27)$ \\
\hline & Black/African American & 139 & $13.94(11.20,16.67)$ \\
\hline & Hispanic & 126 & $13.13(10.11,16.16)$ \\
\hline & Others & 72 & $9.38(5.62,13.14)$ \\
\hline & & 798 & 100.00 \\
\hline \multirow[t]{5}{*}{ Household income } & Less than $\$ 20,000$ & 151 & $20.45(15.13,25.77)$ \\
\hline & $\$ 20,000$-less than $\$ 35,000$ & 96 & $11.87(9.17,14.57)$ \\
\hline & $\$ 35,000$-less than $\$ 50,000$ & 104 & $13.73(10.71,16.75)$ \\
\hline & $\$ 50,000$ or more & 435 & $53.95(49.15,58.76)$ \\
\hline & & 786 & 100.00 \\
\hline \multirow[t]{3}{*}{ Years of education } & High school or less & 164 & $25.06(20.57,29.55)$ \\
\hline & Some college or more & 664 & $74.94(70.45,79.43)$ \\
\hline & & 828 & 100.00 \\
\hline \multirow[t]{3}{*}{ Area: Rurality } & Urban & 813 & $97.75(96.60,98.91)$ \\
\hline & Rural & 21 & $2.25(1.09,3.40)$ \\
\hline & & 834 & 100.00 \\
\hline \multirow[t]{3}{*}{ Employment } & Employed & 501 & $59.54(54.29,64.78)$ \\
\hline & Unemployed & 308 & $40.46(35.22,45.71)$ \\
\hline & & 809 & 0.00 \\
\hline \multirow[t]{3}{*}{ Marital Status } & Married & 499 & 64. $02(58.89,69.14)$ \\
\hline & Not Married & 330 & $35.98(30.86,41.11)$ \\
\hline & & 829 & 100.00 \\
\hline \multirow[t]{5}{*}{ Health Insurance } & By employment or private & 484 & $67.34(62.00,72.68)$ \\
\hline & Tricare, VA, Indian Health Services & 36 & $3.98(1.95,6.11)$ \\
\hline & Medicare & 41 & $3.39(2.04,4.74)$ \\
\hline & Medicaid & 151 & $25.29(20.19,30.40)$ \\
\hline & & 712 & 100.00 \\
\hline
\end{tabular}


Table 2

Caregiver's HPV Awareness/knowledge and Cervical Cancer Screening Behaviors, Frequency (n) and weighted percent (\%)

\begin{tabular}{|c|c|c|c|c|c|c|c|}
\hline & & \multicolumn{2}{|c|}{ HPV Awareness } & \multicolumn{2}{|c|}{ HPV Knowledge } & \multicolumn{2}{|c|}{ Pap Test in 3 Years } \\
\hline & & $\begin{array}{l}\mathrm{N} \\
\text { / row } \\
\text { total }\end{array}$ & $\begin{array}{l}\text { Weighted } \\
\text { percent } \\
(95 \% \mathrm{Cl})\end{array}$ & $\begin{array}{l}\mathrm{N} \\
\text { /row } \\
\text { total }\end{array}$ & $\begin{array}{l}\text { Weighted } \\
\text { percent } \\
(95 \% \mathrm{Cl})\end{array}$ & $\begin{array}{l}\mathrm{N} / \\
\text { row } \\
\text { total }\end{array}$ & $\begin{array}{l}\text { Weighted } \\
\text { percent } \\
(95 \% \mathrm{Cl})\end{array}$ \\
\hline & Total & $661 / 834$ & $79 \%$ & $547 / 560$ & $98 \%$ & $671 / 805$ & $83 \%$ \\
\hline age (years) & $21-50$ & $369 / 432$ & $\begin{array}{l}84 \% \\
(79 \%, 89 \%)\end{array}$ & $318 / 324$ & $\begin{array}{l}98 \% \\
(96 \%, 100 \%)\end{array}$ & $381 / 416$ & $\begin{array}{l}91 \% \\
(88 \%, 94 \%)\end{array}$ \\
\hline & $51-65$ & $292 / 402$ & $\begin{array}{l}66 \% \\
(58 \%, 75 \%)\end{array}$ & $229 / 236$ & $\begin{array}{l}98 \% \\
(96 \%, 100 \%)\end{array}$ & $290 / 389$ & $\begin{array}{l}75 \% \\
(69 \%, 81 \%)\end{array}$ \\
\hline \multirow[t]{4}{*}{$\begin{array}{l}\text { Race/ } \\
\text { ethnicity }\end{array}$} & White & $400 / 460$ & $\begin{array}{l}84 \% \\
(79 \%, 89 \%)\end{array}$ & $340 / 345$ & $\begin{array}{l}99 \% \\
(97 \%, 100 \%)\end{array}$ & $373 / 451$ & $\begin{array}{l}83 \% \\
(79 \%, 87 \%)\end{array}$ \\
\hline & $\begin{array}{l}\text { Black/African } \\
\text { American }\end{array}$ & $100 / 139$ & $\begin{array}{l}69 \% \\
(57 \%, 80 \%)\end{array}$ & $79 / 81$ & $\begin{array}{l}99 \% \\
(96 \%, 100 \%)\end{array}$ & $114 / 132$ & $\begin{array}{l}88 \% \\
(80 \%, 96 \%)\end{array}$ \\
\hline & Hispanic & $94 / 126$ & $\begin{array}{l}77 \% \\
(67 \%, 87 \%)\end{array}$ & $74 / 75$ & $\begin{array}{l}98 \% \\
(95 \%, 100 \%)\end{array}$ & $96 / 119$ & $\begin{array}{l}77 \% \\
(68 \%, 87 \%)\end{array}$ \\
\hline & Others & $17 / 34$ & $\begin{array}{l}53 \% \\
(31 \%, 76 \%)\end{array}$ & $15 / 15$ & $\begin{array}{l}93 \% \\
(81 \%, 100 \%)\end{array}$ & $30 / 32$ & $\begin{array}{l}94 \% \\
(88 \%, 100 \%)\end{array}$ \\
\hline \multirow[t]{4}{*}{$\begin{array}{l}\text { Household } \\
\text { income }\end{array}$} & Less than $\$ 20,000$ & $104 / 150$ & $\begin{array}{l}70 \% \\
(56 \%, 84 \%)\end{array}$ & $76 / 82$ & $\begin{array}{l}98 \% \\
(95 \%, 100 \%)\end{array}$ & $113 / 143$ & $\begin{array}{l}80 \% \\
(71 \%, 89 \%)\end{array}$ \\
\hline & $\$ 20,000$ to $<\$ 35,000$ & $64 / 96$ & $\begin{array}{l}69 \% \\
(57 \%, 82 \%)\end{array}$ & $48 / 50$ & $\begin{array}{l}95 \% \\
(85 \%, 100 \%)\end{array}$ & $65 / 91$ & $\begin{array}{l}86 \% \\
(79 \%, 94 \%)\end{array}$ \\
\hline & $\$ 35,000$ to $<\$ 50,000$ & $78 / 104$ & $\begin{array}{l}78 \% \\
(66 \%, 90 \%)\end{array}$ & $58 / 60$ & $\begin{array}{l}95 \% \\
(88 \%, 100 \%)\end{array}$ & $82 / 101$ & $\begin{array}{l}80 \% \\
(70 \%, 89 \%)\end{array}$ \\
\hline & $\$ 50,000$ or more & $383 / 435$ & $\begin{array}{l}82 \% \\
(75 \%, 89 \%)\end{array}$ & $338 / 341$ & $\begin{array}{l}99 \% \\
(98 \%, 100 \%)\end{array}$ & $374 / 425$ & $\begin{array}{l}87 \% \\
(82 \%, 91 \%)\end{array}$ \\
\hline $\begin{array}{l}\text { Years of } \\
\text { education }\end{array}$ & $\begin{array}{l}\text { High school or less } \\
\text { Some college or more }\end{array}$ & $\begin{array}{l}98 / 164 \\
559 / 663\end{array}$ & $\begin{array}{l}61 \% \\
(49 \%, 73 \%) \\
83 \% \\
(78 \%, 88 \%)\end{array}$ & $\begin{array}{l}61 / 68 \\
482 / 488\end{array}$ & $\begin{array}{l}96 \% \\
(93 \%, 100 \%) \\
98 \% \\
(97 \%, 100 \%)\end{array}$ & $\begin{array}{l}115 / 153 \\
553 / 648\end{array}$ & $\begin{array}{l}76 \% \\
(67 \%, 85 \%) \\
87 \% \\
(84 \%, 90 \%)\end{array}$ \\
\hline \multirow[t]{2}{*}{ Employment } & Employed & $407 / 501$ & $\begin{array}{l}78 \% \\
(71 \%, 86 \%)\end{array}$ & $348 / 354$ & $\begin{array}{l}98 \% \\
(96 \%, 100 \%)\end{array}$ & $410 / 484$ & $\begin{array}{l}85 \% \\
(81 \%, 90 \%)\end{array}$ \\
\hline & Unemployed & $234 / 307$ & $\begin{array}{l}74 \% \\
(67 \%, 82 \%)\end{array}$ & $185 / 192$ & $\begin{array}{l}98 \% \\
(96 \%, 100 \%)\end{array}$ & $241 / 298$ & $\begin{array}{l}83 \% \\
(77 \%, 88 \%)\end{array}$ \\
\hline \multirow[t]{2}{*}{ Marital Status } & Married & $413 / 499$ & $\begin{array}{l}81 \% \\
(75 \%, 86 \%)\end{array}$ & $354 / 360$ & $\begin{array}{l}98 \% \\
(96 \%, 100 \%)\end{array}$ & $417 / 487$ & $\begin{array}{l}85 \% \\
(81 \%, 89 \%)\end{array}$ \\
\hline & Not Married & $245 / 329$ & $\begin{array}{l}72 \% \\
(63 \%, 80 \%)\end{array}$ & $191 / 198$ & $\begin{array}{l}99 \% \\
(98 \%, 100 \%)\end{array}$ & $249 / 313$ & $\begin{array}{l}83 \% \\
(78 \%, 89 \%)\end{array}$ \\
\hline Health & Employment/ private & $418 / 484$ & $83 \%$ & $365 / 368$ & $99 \%$ & $412 / 472$ & $88 \%$ \\
\hline
\end{tabular}

Page 13/14 


\begin{tabular}{|c|c|c|c|c|c|c|c|}
\hline Insurance & & & $(75 \%, 90 \%)$ & & $(98 \%, 100 \%)$ & & $(84 \%, 92 \%)$ \\
\hline & $\begin{array}{l}\text { Tricare/VA/Indian } \\
\text { Health }\end{array}$ & $28 / 36$ & $\begin{array}{l}81 \% \\
(64 \%, 98 \%)\end{array}$ & $24 / 25$ & $\begin{array}{l}99 \% \\
(96 \%, 100 \%)\end{array}$ & $29 / 35$ & $\begin{array}{l}91 \% \\
(81 \%, 100 \%\end{array}$ \\
\hline & Medicare & $32 / 40$ & $\begin{array}{l}76 \% \\
(56 \%, 96 \%)\end{array}$ & $23 / 24$ & $\begin{array}{l}88 \% \\
(62 \%, 100 \%)\end{array}$ & $30 / 38$ & $\begin{array}{l}86 \% \\
(73 \%, 100 \%)\end{array}$ \\
\hline & Medicaid & $109 / 151$ & $\begin{array}{l}73 \% \\
(62 \%, 84 \%)\end{array}$ & $82 / 87$ & $\begin{array}{l}96 \% \\
(92 \%, 100 \%)\end{array}$ & $124 / 147$ & $\begin{array}{l}83 \% \\
(75 \%, 91 \%)\end{array}$ \\
\hline
\end{tabular}

Table 3

HPV Awareness and Knowledge and Cervical Cancer Screening Behaviors Among Caregivers (Odds Ratio and 95\% Cl)

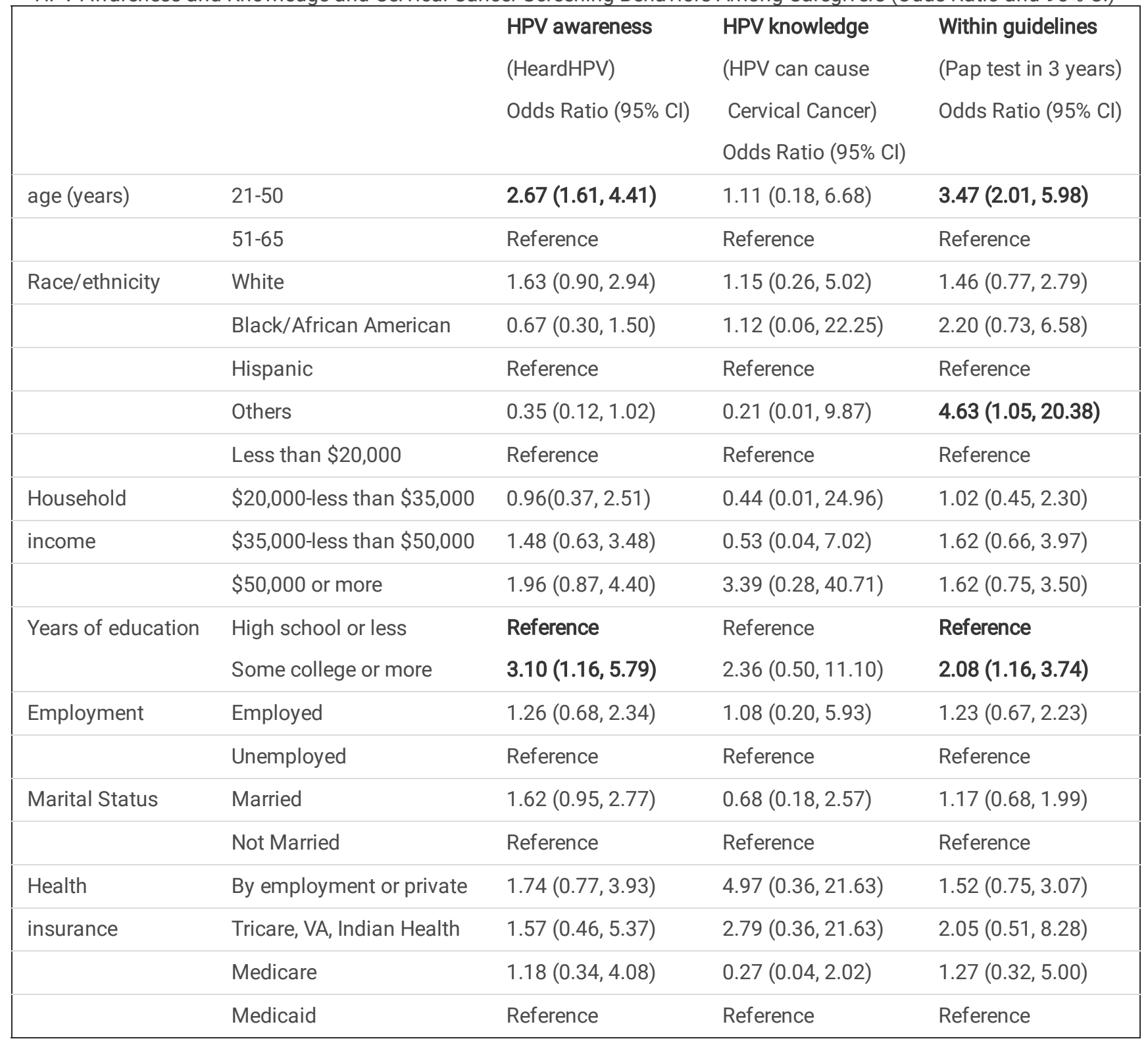

*Bold-coded is statistically significant, P-value $<0.05$. 